\title{
Disease progression in idiopathic pulmonary fibrosis with mild physiological impairment: analysis from the Australian IPF registry
}

Helen E. Jo ${ }^{1,2^{*}}$ (D) lan Glaspole ${ }^{3}$, Yuben Moodley ${ }^{4}$, Sally Chapman ${ }^{5}$, Samantha Ellis ${ }^{3}$, Nicole Goh ${ }^{3,6}$, Peter Hopkins ${ }^{7}$, Greg Keir ${ }^{8}$, Annabelle Mahar ${ }^{1}$, Wendy Cooper ${ }^{1,2,9}$, Paul Reynolds ${ }^{5}$, E. Haydn Walters ${ }^{10,11}$, Christopher Zappala ${ }^{12}$, Christopher Grainge ${ }^{13}$, Heather Allan ${ }^{14}$, Sacha Macansh ${ }^{14}$ and Tamera J. Corte ${ }^{1,2}$

\begin{abstract}
Background: Idiopathic pulmonary fibrosis (IPF) is a progressive and fatal fibrosing lung disease of unknown cause. The advent of anti-fibrotic medications known to slow disease progression has revolutionised IPF management in recent years. However, little is known about the natural history of IPF patients with mild physiological impairment. We aimed to assess the natural history of these patients using data from the Australian IPF Registry (AIPFR).

Methods: Using our cohort of real-world IPF patients, we compared FVC criteria for mild physiological impairment (FVC $\geq 80 \%$ ) against other proposed criteria: DLCO $\geq 55 \%$; CPI $\leq 40$ and GAP stage 1 with regards agreement in classification and relationship with disease outcomes. Within the mild cohort (FVC $\geq 80 \%)$, we also explored markers associated with poorer prognosis at 12 months.

Results: Of the 416 AIPFR patients (mean age 70.4 years, 70\% male), 216 (52\%) were classified as 'mild' using FVC $\geq$ $80 \%$. There was only modest agreement between FVC and DLCo $(k=0.30)$, with better agreement with GAP $(k=0.50)$ and CPI $(k=0.48)$. Patients who were mild had longer survival, regardless of how mild physiologic impairment was defined. There was, however, no difference in the annual decline in FVC\% predicted between mild and moderate-severe groups (for all proposed criteria). For patients with mild impairment ( $n=216, F V C \geq 80 \%$ ), the strongest predictor of outcomes at 12 months was oxygen desaturation on a 6 min walk test.
\end{abstract}

Conclusion: IPF patients with mild physiological impairment have better survival than patients with moderate-severe disease. Their overall rate of disease progression however, is comparable, suggesting that they are simply at different points in the natural history of IPF disease.

Keywords: Idiopathic pulmonary fibrosis, Interstitial lung disease, Disease severity

\section{Background}

Idiopathic pulmonary fibrosis (IPF), a progressive fibrosing interstitial lung disease (ILD) of unknown cause, results in respiratory failure and ultimately death. Historically the median survival is thought to be only 2-5 years [1], and the incidence of IPF appears to be

\footnotetext{
* Correspondence: helen.jo@sydney.edu.au

${ }^{1}$ Royal Prince Alfred Hospital, Missenden Road, Camperdown, NSW 2050, Australia

${ }^{2}$ University of Sydney, Camperdown, NSW, Australia

Full list of author information is available at the end of the article
}

increasing globally [2]. Recently, two agents - nintedanib and pirfenidone - have demonstrated efficacy in slowing the rate of FVC decline as well as impacting on a number of other important disease outcomes [3-6]. However, each trial focused on cohorts with moderate physiologic impairment and the ASCEND trial excluded subjects with a forced vital capacity (FVC) above 90\% predicted [3]. Although post-hoc analyses demonstrate comparable responses to anti-fibrotic therapy between participants with preserved lung volumes and those with more significant impairment, access to anti-fibrotic 
medications has been excluded from patients with lesser physiological impairment in several drug jurisdictions due to the limited nature of efficacy data for this cohort $[7,8]$.

There have been various attempts to define severity of IPF [9-11]. Physiologic measurements, such as FVC or diffusion capacity for carbon monoxide (DLco) have been commonly used [12, 13], as have composite measures of several physiologic values or demographic features $[14,15]$. The two most commonly used composite scores are the composite physiological index (CPI) [14] and the GAP (gender, age and physiology) stage [15]. While both individual physiologic measurements and composite scores predict mortality, the ability of each to distinguish differences in disease progression among those with mild disease from those more significantly affected remains unknown. Clinically, the FVC has been used not only as a clinical trial endpoint, but also by funding authorities worldwide to limit access to anti-fibrotic medications.

The Australian IPF Registry (AIPFR), launched in 2012, recruits IPF patients from across Australia and a broad spectrum of impairment exists within its data set. Using this cohort, we sought to compare the FVC $\geq 80 \%$ with other severity criteria in their ability to distinguish differences in death and disease progression as measured by annual FVC decline, between mild and moderatesevere cohorts. Additionally, we investigated factors predicting poorer prognosis for patients with mild physiological impairment, to ascertain whether further characterisation may help select patients who would especially merit early drug intervention.

\section{Methods}

\section{Participants}

The Australian IPF Registry is a multi-centre, prospective, observational registry of incident and prevalent IPF patients across Australia. Details regarding the Australian IPF Registry data collection, structure and operations have previously been published [16]. The Registry has ethical approval to operate in all States and Territories and this analysis has ethical approval from the Sydney Local Health District ethics committee (protocol No X14-0264). All participants in the Registry were eligible for inclusion in this analysis.

\section{Classification of mild disease}

Using data from the Registry, patients were categorised as having mild physiological impairment using four different criteria. The primary analysis focused on FVC $\geq$ $80 \%$ predicted (exploratory analysis for $\mathrm{FVC} \geq 90 \%$ $\mathrm{FVC} \geq 75 \%, \mathrm{FVC} \geq 70 \%$ ) [13], as this is the criteria used clinically to restrict anti-fibrotic therapies in many regions. Secondary analysis included: DLco $\geq 55 \%$ (exploratory analysis of DLco $\geq 50 \%$, DLco $\geq 40 \%$, DLco $\geq 30 \%$ )
[12]; $\mathrm{CPI} \leq 40$ (exploratory analysis $\mathrm{CPI} \leq 30, \mathrm{CPI} \leq 50$ )

[14]; GAP stage 1 [15].

Only patients who had all the necessary information for calculation of all scores were included. The CPI was calculated using the formula: CPI $=91.0-(0.65 \times \%$ predicted DLco $)-(0.53 \times \%$ predicted FVC $)+(0.34 \times \%$ predicted $\mathrm{FEV}_{1}$ ) [14]. The GAP score was calculated using gender, age and physiology as outlined in Additional file 1: Table S1 [15].

\section{Statistical methods}

Data are presented as mean \pm standard deviation (SD) and also range, or $\mathrm{n}(\%)$, as appropriate. The agreement between the different criteria used to define mild impairment was assessed using kappa values. Univariable and multivariable Cox proportional models were performed to investigate the relationships between baseline variables, including disease severity classifications, with survival. All patients who received lung transplantation were censored at the date of transplant for time to event analyses. Survival curves were compared using the Kaplan-Meier method and log rank test.

An unstructured, linear mixed model for changes in FVC \% predicted per year was fitted with random intercepts and slopes to compare the disease trajectory for patients with mild compared with moderate-severe physiological impairment, over the entire time of patient follow up in the Registry. Finally, logistic regression assessing a composite end-point of death or disease progression (defined as a relative fall in $\mathrm{FVC} \geq 10 \%$ and/or DLco $\geq 15 \%$ from baseline) at 12 months was performed in patients with mild impairment (FVC $\geq 80 \%)$ at baseline, to determine markers associated with poorer shortterm prognosis in this group.

\section{Results}

\section{Baseline characteristics}

Of the 647 patients in the Australian IPF Registry, there were 416 patients who had complete data for severity score measurements at baseline, and so available for inclusion in this study. Their baseline characteristics are displayed in Table 1. Interestingly, though less severe, patients with mild physiological impairment still had significant symptoms as measured by the St George Respiratory Questionnaire (SGRQ) and University of California San Diego shortness of breath Questionnaire (UCSD SOBQ). Comparisons of baseline demographic parameters of patients excluded from this analysis are available in Additional file 2: Table S2. Overall, patients who were excluded were slightly older and had more severe symptoms, similar to patients categorised as severe impairment using FVC $\leq 80 \%$ criteria (Table 1 ).

There were 114 deaths (27.4\%) over a median follow up period of 2.09 years (IQR 1.56, 2.78 years) providing 
Table 1 Baseline characteristics of patients in the Australian IPF Registry

\begin{tabular}{|c|c|c|c|c|c|c|c|}
\hline \multirow[t]{2}{*}{ Variable } & \multirow[t]{2}{*}{$\mathrm{n}$} & \multirow[t]{2}{*}{ overall } & \multirow{2}{*}{$\begin{array}{l}\text { Mild (FVC } \geq 80 \%) \\
216\end{array}$} & $\begin{array}{l}\text { Moderate-Severe } \\
\text { (FVC }<80 \%)\end{array}$ & \multirow[t]{2}{*}{$\mathrm{P}^{\mathrm{a}}$} & \multirow[t]{2}{*}{ Min } & \multirow[t]{2}{*}{ Max } \\
\hline & & & & 200 & & & \\
\hline Age, years & 416 & $70.4(8.6)$ & $71.6(7.9)$ & $69.0(9.1)$ & 0.003 & 31.5 & 89.9 \\
\hline Male, n (\%) & 416 & $290(69.7 \%)$ & 125 (57.9\%) & 165 (82.5\%) & $<0.001$ & & \\
\hline Ever smoker, n (\%) & 416 & $308(74.0 \%)$ & $160(74 \%)$ & $148(74 \%)$ & 0.986 & & \\
\hline $\mathrm{BMI}, \mathrm{kg} / \mathrm{m}^{2}$ & 412 & $28.8(4.8)$ & $28.9(5.0)$ & $28.6(4.6)$ & 0.565 & 15.8 & 46.4 \\
\hline FVC, L & 416 & $2.6(0.8)$ & $2.96(0.79)$ & $2.30(0.54)$ & $<0.001$ & 0.9 & 4.8 \\
\hline FVC, \% pred & 416 & $81.7(21.2)$ & $97.3(16.6)$ & $64.9(9.8)$ & $<0.001$ & 40.9 & 219.5 \\
\hline $\mathrm{FEV}_{1} / \mathrm{FVC}$ ratio\% & 416 & $82.2(8.4)$ & 80.1 (8.6) & $84.4(7.5)$ & $<0.001$ & 27.0 & 135.0 \\
\hline DLco, \% pred & 416 & $48.5(16.8)$ & $54.6(17.4)$ & $41.8(13.2)$ & $<0.001$ & $9.4 \%$ & $143.7 \%$ \\
\hline $\mathrm{CPI}$ & 416 & $45.1(14.1)$ & $37.5(13.2)$ & $53.3(9.7)$ & $<0.001$ & 54.2 & 74.5 \\
\hline GAP stage & 416 & & & & $<0.001$ & & \\
\hline GAP stage 1 & & $192(46.2 \%)$ & $152(70.4 \%)$ & $40(20.0 \%)$ & & & \\
\hline GAP stage 2 & & $186(44.7 \%)$ & $64(29.6 \%)$ & $122(61.0 \%)$ & & & \\
\hline GAP stage 3 & & 38 (9.1\%) & $0(0 \%)$ & $38(19.0 \%)$ & & & \\
\hline 6MWT distance, $\mathrm{m}$ & 164 & $431.0(119)$ & $433(115)$ & $430(122)$ & 0.894 & 48.0 & 706.0 \\
\hline Initial $\mathrm{SpO}_{2} \%$ & 163 & 95.5 (3.19) & $95.8(3.4)$ & $95.4(3.1)$ & 0.482 & 83.0 & 100.0 \\
\hline End $\mathrm{SpO}_{2}, \%$ & 160 & $86.2(7.2)$ & $89.0(7.0)$ & $84.4(6.8)$ & $<0.001$ & 58.0 & 99.0 \\
\hline Nadir $\mathrm{SpO}_{2}, \%$ & 153 & $85.3(7.1)$ & $87.9(7.3)$ & $83.6(6.5)$ & $<0.001$ & 58.0 & 99.0 \\
\hline SGRQ & 383 & $43.0(19.7)$ & 38.7 (19.0) & $47.6(44.8)$ & $<0.001$ & 0.0 & 96.6 \\
\hline UCSD SOBQ & 243 & $40.8(29.3)$ & $33.7(27.1)$ & $48.6(29.6)$ & $<0.001$ & 0.0 & 119.0 \\
\hline Cough severity & 347 & $39.5(23.5)$ & $36.9(22.9)$ & $42.3(23.9)$ & 0.034 & 0.0 & 100.0 \\
\hline Anti-fibrotic therapy & 416 & $102(24.5 \%)$ & $52(24.1 \%)$ & $50(25.0 \%)$ & 0.826 & & \\
\hline
\end{tabular}

${ }^{a}$ comparison between mild and severe physiological impairment

914 patient-years of follow up. 17 (4.1\%) patients underwent lung transplantation during the follow up period.

\section{Agreement of proposed criteria for mild IPF}

The FVC $\geq 80 \%$ categorised almost equal numbers of patients as having mild $(n=216,52 \%)$ compared to moderate-severe impairment $(n=200,48 \%)$, while a DLco $\geq 55 \%$ classified the least patients as having mild disease $(n=131,32 \%)$ (Fig. 1). We also undertook exploratory analysis of other threshold levels and as expected, the change in threshold values had a significant impact on the proportion of patients classified as mild for FVC, DLco and in particular CPI (Additional file 3: Figure S1).

Mild physiological impairment defined by $\mathrm{FVC} \geq 80 \%$ had modest agreement with GAP stage $1(\mathrm{k}=0.50)$ and $\mathrm{CPI} \leq 40(\mathrm{k}=0.48)$ and only fair agreement with DLco $\geq$ $55 \%(\mathrm{k}=0.30)$. CPI $\leq 40$ had the best agreement with other variables including DLco $\geq 55 \%(\mathrm{k}=0.74)$ and GAP

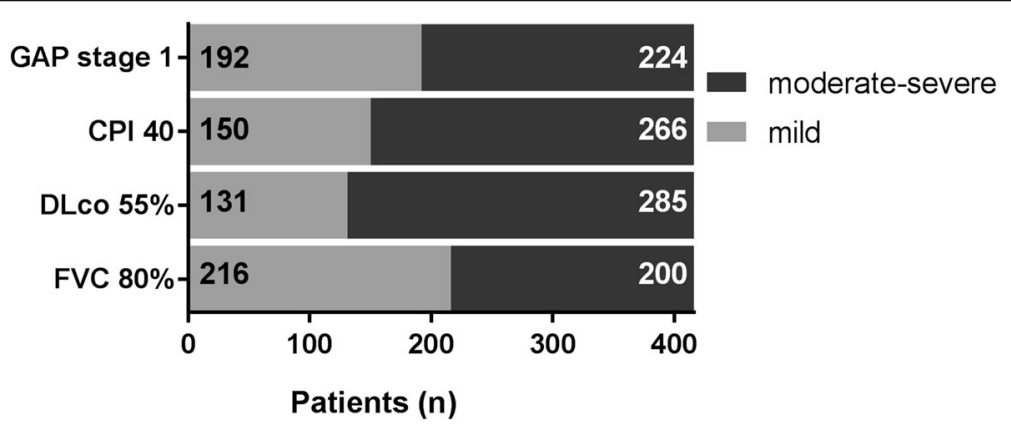

Fig. 1 Classification as mild disease using different mild definitions 
stage $1(\mathrm{k}=0.68)$. There was good agreement between GAP stage 1 and DLco $\geq 55 \%(\mathrm{k}=0.61)$.

\section{Factors predictive of death}

As demonstrated in Table 2, on univariable analysis, demographic characteristics (age, gender, BMI, smoking status), physiology, and symptom scores (SGRQ, UCSD SOBQ), except cough severity (measured at baseline on a visual analogue scale), all predicted increased mortality for the entire IPF population.

The presence of mild impairment at baseline (by all proposed criteria) was also predictive of better survival than those patients with moderate-severe disease, on univariable as well as multivariable analysis including age, gender, BMI and smoking status (Table 3). There was a wide separation in the Kaplan-Meier curves for mild versus moderate-severe physiological impairment (Fig. 2).

\section{Disease progression}

The disease progression of patients with mild impairment, measured as change in FVC \% predicted per year compared to those with moderate-severe impairment are shown in Table 4 and Fig. 3. There was no difference in the annual rate of $\mathrm{FVC} \%$ predicted decline between the

Table 2 Univariable Cox analysis

\begin{tabular}{|c|c|c|c|c|c|}
\hline \multirow[b]{2}{*}{ Age } & \multirow{2}{*}{$\begin{array}{l}\mathrm{n} \\
416\end{array}$} & \multirow{2}{*}{$\begin{array}{l}\mathrm{HR} \\
1.03\end{array}$} & \multicolumn{2}{|c|}{$95 \% \mathrm{Cl}$} & \multirow{2}{*}{$\frac{p}{0.013}$} \\
\hline & & & 1.01 & 1.05 & \\
\hline male & 416 & 1.96 & 1.25 & 3.08 & 0.003 \\
\hline BMI & 412 & 0.94 & 0.89 & 0.98 & 0.003 \\
\hline Smoking & 416 & 1.93 & 1.20 & 3.11 & 0.007 \\
\hline \multicolumn{6}{|l|}{ Physiology } \\
\hline FVC (L) & 416 & 0.56 & 0.43 & 0.74 & $<0.001$ \\
\hline FVC (\%pred) $)^{a}$ & 416 & 0.71 & 0.64 & 0.79 & $<0.001$ \\
\hline DLCo (\%pred) $)^{a}$ & 416 & 0.56 & 0.49 & 0.64 & $<0.001$ \\
\hline $6 \mathrm{MWD}^{\mathrm{b}}$ & 164 & 0.82 & 0.73 & 0.92 & 0.001 \\
\hline $\mathrm{SpO} 2$ at rest & 163 & 0.88 & 0.82 & 0.95 & 0.001 \\
\hline SpO2 at end & 160 & 0.92 & 0.88 & 0.95 & $<0.001$ \\
\hline SpO2 nadir & 153 & 0.92 & 0.89 & 0.96 & $<0.001$ \\
\hline $\mathrm{CPI}$ & 416 & 1.09 & 1.07 & 1.11 & $<0.001$ \\
\hline GAP stage & 416 & 4.48 & 3.37 & 5.95 & $<0.001$ \\
\hline \multicolumn{6}{|c|}{ Patient reported outcomes } \\
\hline SGRQ total ${ }^{c}$ & 383 & 1.11 & 1.06 & 1.15 & $<0.001$ \\
\hline UCSD SOBQ & 243 & 1.23 & 1.13 & 1.33 & $<0.001$ \\
\hline Cough severity $^{a}$ & 347 & 1.08 & 0.99 & 1.17 & 0.069 \\
\hline
\end{tabular}

$B M I$ body mass index, FVC forced vital capacity, DLco diffusion capacity for carbon monoxide, $C P I$ composite physiological index, GAP gender age physiology, $6 M W D$ 6 min walk distance, SpO2 peripheral blood oxygen saturation, SGRQ St George's Respiratory Questionniare, UCSD-SOBQ University of California San Diego shortness of breath questionnaire. ${ }^{\mathrm{a}}$ For every 10 unit change; ${ }^{\mathrm{b}}$ for every $50 \mathrm{~m}$ change; ' for every 4 point change
Table 3 Univariable and multivariable Cox analysis for disease severity

\begin{tabular}{llllllll}
\hline & HR & $95 \% \mathrm{Cl}$ & $\mathrm{p}$ & $\mathrm{HR}$ & $95 \% \mathrm{Cl}$ & $\mathrm{p}$ \\
& \multicolumn{3}{l}{ Univariable analysis } & & \multicolumn{4}{c}{ Multivariable analysis $^{\mathrm{a}}$} \\
\hline $\mathrm{FVC}<80 \%$ & 3.21 & $2.17-4.75$ & $<0.001$ & 3.15 & $2.11-4.71$ & $<0.001$ \\
DLCO $<55 \%$ & 6.28 & $3.28-12.03$ & $<0.001$ & 5.55 & $2.88-10.70$ & $<0.001$ \\
$\mathrm{CPI}>40$ & 7.28 & $3.90-13.57$ & $<0.001$ & 6.60 & $3.52-12.39$ & $<0.001$ \\
GAP stage 1 & 7.09 & $4.27-11.76$ & $<0.001$ & 7.44 & $4.18-13.25$ & $<0.001$ \\
\hline
\end{tabular}

aMultivariable model includes age, gender, $\mathrm{BMI}$ and smoking status and

includes 412 of 416 available for univariable model

mild and moderate-severe cohorts, regardless of the disease severity classification used, with the predicted annual fall for the entire cohort calculated at 4.4 units (of FVC \% predicted)/year. In a exploratory analysis, locally weighted scatterplots of FVC\% predicted were constructed for patients with mild and moderate-severe disease and again demonstrated similar disease trajectories in these groups (Additional file 4: Figure S2).

Factors predicting progression or death at 12 month in the mild disease group

There were 216 patients with $\mathrm{FVC} \geq 80 \%$ categorised as having mild impairment. Overall, these patients had preserved lung volume with a mean FVC of $97.3 \%$ predicted, DLco of $54.6 \%$ predicted and were mostly categorised as GAP stage 1 (70.4\%) with the remainder as GAP stage 2 (29.6\%). Unsurprisingly, they were less symptomatic than those with more severe disease, though they still had significant symptoms. Interestingly, patients with mild impairment were slightly older and more likely to be female (Table 1).

Within the cohort of patients with mild impairment, the prognostic markers which predicted death or progression at 12 months were evaluated using univariable logistic regression. There were 22 patients $(10.2 \%)$ who died or progressed within 12 months. The only factor that predicted death or progression at 12 months was oxygen desaturation during 6 min walk testing at baseline (OR $0.89,95 \%$ CI $0.81,0.98 ; p=0.024$ for every $1 \%$ change in nadir $\mathrm{SpO}_{2}$ ) (Table 5).

Unsurprisingly, within this cohort with mild impairment, other lung function parameters and composite scores were not predictive of death or progression. On a multivariable logistic regression model including age, gender, BMI and smoking status, nadir oxygen saturation during $6 \mathrm{MWT}$ remained a significant predictor of poorer outcome (OR 0.89, 95\%CI 0.80, 0.98; $\mathrm{p}=0.024$ ).

\section{Discussion}

In our cohort of IPF patients from the Australian IPF Registry, we demonstrate that a significant proportion of 


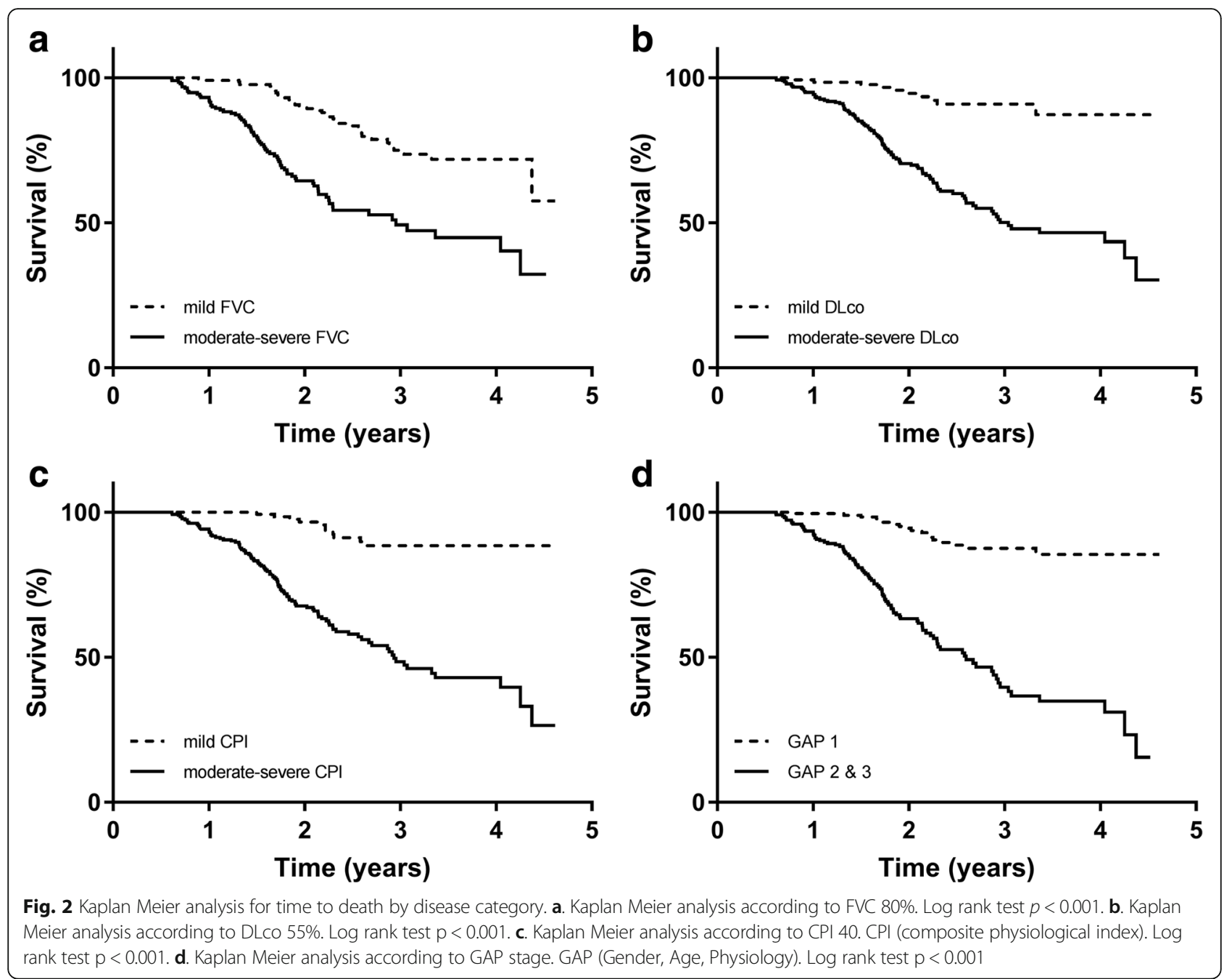

IPF patients have mild physiological impairment; though this proportion varied depending on the criteria and threshold used to define mild impairment. We demonstrate that the agreement for mild impairment using FVC $\geq 80 \%$ was modest to fair with other proposed criteria. We also show that patients who are mild have better survival than patients those with moderate-severe physiological impairment. Importantly, we show that patients with mild impairment, regardless of the criteria for categorisation used, have a similar annual rate of

Table 4 Annual FVC \% predicted decline by disease category and severity

\begin{tabular}{llllll}
\hline & mild & $95 \% \mathrm{Cl}$ & more severe & $95 \% \mathrm{Cl}$ & $\mathrm{P}^{\mathrm{a}}$ \\
\hline FVC & $-4.6 \%$ & $-5.8 ;-3.4 \%$ & $-4.9 \%$ & $-6.3 ;-3.5 \%$ & 0.779 \\
DLCO & $-4.9 \%$ & $-6.0 ;-3.8 \%$ & $-4.7 \%$ & $-5.7 ;-3.7 \%$ & 0.702 \\
CPI & $-5.0 \%$ & $-6.3 ;-3.6 \%$ & $-4.5 \%$ & $-5.7 ;-3.3 \%$ & 0.600 \\
GAP & $-5.0 \%$ & $-6.3 ;-3.8 \%$ & $-4.4 \%$ & $-5.8 ;-3.0 \%$ & 0.517 \\
\hline
\end{tabular}

${ }^{\mathrm{a}}$ comparison of mild to moderate-severe group

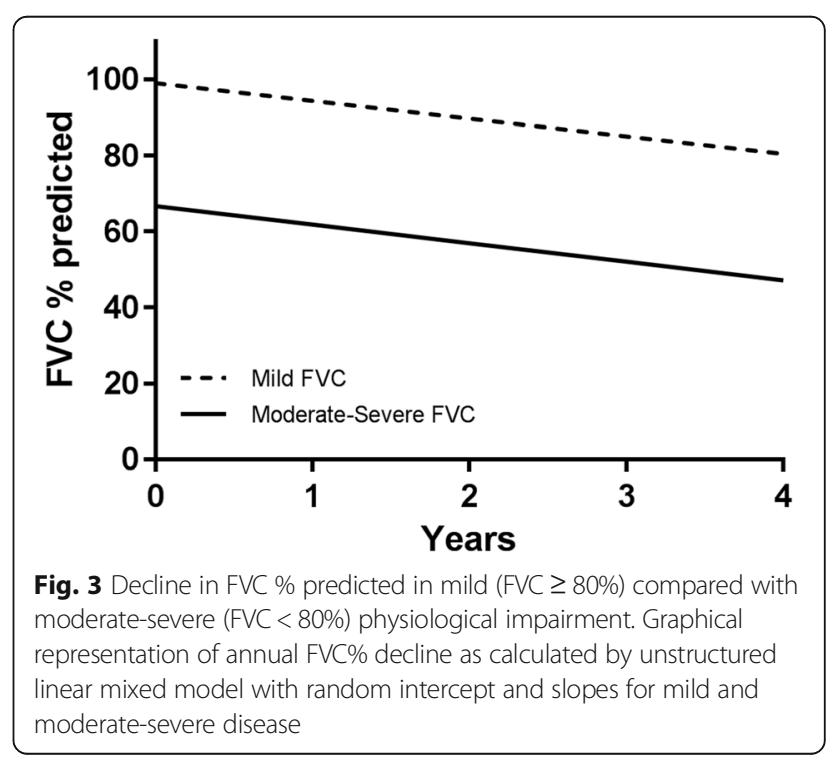


Table 5 Logistic regression for death or disease progression at 12 months in patients with FVC $\geq 80 \%$

\begin{tabular}{|c|c|c|c|c|c|}
\hline & $n$ & OR & $95 \%$ & & $p$ \\
\hline Age & 216 & 0.99 & 0.94 & 1.05 & 0.847 \\
\hline male & 216 & 0.86 & 0.35 & 2.09 & 0.739 \\
\hline BMI & 212 & 1.00 & 0.92 & 1.10 & 0.954 \\
\hline Ever smoker & 216 & 0.93 & 0.34 & 2.50 & 0.879 \\
\hline FVC $\%$ pred $^{a}$ & 216 & 0.81 & 0.56 & 1.16 & 0.241 \\
\hline DLco \%pred ${ }^{a}$ & 216 & 0.87 & 0.67 & 1.14 & 0.312 \\
\hline $\mathrm{CPI}^{\mathrm{a}}$ & 216 & 1.26 & 0.86 & 1.86 & 0.234 \\
\hline GAP stage & 216 & 1.12 & 0.43 & 2.90 & 0.813 \\
\hline $6 \mathrm{MWD}^{\mathrm{b}}$ & 63 & 0.75 & 0.54 & 1.04 & 0.083 \\
\hline $\mathrm{SpO} 2$ at start & 63 & 0.86 & 0.71 & 1.03 & 0.108 \\
\hline $\mathrm{SpO} 2$ at end & 63 & 0.89 & 0.81 & 0.98 & 0.021 \\
\hline SpO2 nadir & 59 & 0.89 & 0.81 & 0.98 & 0.024 \\
\hline $\mathrm{SGRQ}^{\mathrm{c}}$ & 199 & 1.02 & 0.93 & 1.12 & 0.688 \\
\hline UCSD SOBQ ${ }^{a}$ & 126 & 1.00 & 0.77 & 1.28 & 0.970 \\
\hline Cough severity $^{a}$ & 177 & 1.16 & 0.95 & 1.41 & 0.136 \\
\hline
\end{tabular}

BMI body mass index, FVC forced vital capacity, DLco diffusion capacity for carbon monoxide, CPI composite physiological index, GAP gender age physiology, $6 M W D$ 6 min walk distance, SpO2 peripheral blood oxygen saturation, SGRQ St George's Respiratory Questionniare, UCSD-SOBQ University of California San Diego shortness of breath questionnaire. ${ }^{a}$ For every 10 unit change; ${ }^{b}$ for every $50 \mathrm{~m}$ change; ${ }^{\mathrm{C}}$ for every 4 point change

decline in FVC \% predicted compared to those with more severe impairment. Finally, we show that in patients with mild impairment, the prognostic marker most predictive of death or progression at 12 months was oxygen desaturation on the 6 min walk test (6MWT).

One important finding of this study was that IPF patients with mild physiological impairment had the same disease trajectory, with comparable annual decline in FVC to those with moderate-severe disease. This mirrors the results found in the post-hoc analysis of pirfenidone [8] and nintedanib trial cohorts [7] whereby patients with mild physiological impairment were shown to have comparable disease progression at 12 months to their more severe counterparts. Unlike the clinical trial cohorts however, Registry patients are real-world, unselected IPF patients with frequent significant comorbidities. Registry patients also have a wide spectrum of IPF disease severity with 68 patients below the threshold for inclusion in clinical trials $(\mathrm{FVC}<50 \%, n=9$; DLco $<30 \% n=47$, and $n=6$ for both), and are managed by respiratory physicians throughout Australia, not limited to tertiary referral centres. The reproducibility of this finding in this heterogeneous cohort strengthens the generalisability of the post-hoc analysis from the large therapeutic clinical trials $[7,8]$. It is also important to note that even patients with mild physiological impairment had significant symptoms. Ultimately, these results suggest that patients with preserved physiology are likely to represent an earlier stage of the natural history of IPF, rather than a separate and milder cohort of IPF patients with a specific natural history.

Another important finding of our study was that within the cohort of patients with mild impairment, the degree of oxygen desaturation on the 6MWT was the only significant short-term prognostic marker. Whilst previous studies have demonstrated that the 6MWT distance [17-19] and oxygen desaturation [20, 21] on $6 \mathrm{MWT}$ can predict mortality in IPF, this test is often not performed on a regular basis (as demonstrated in this study by the smaller number of patients who have had this test). The desaturation on the 6MWT is likely to represent a complex interplay between, and cumulative impact of, the physiological changes that occur in IPF including pulmonary hypertension, ventilation/perfusion mismatch and diffusion limitation. Our data suggests that in a cohort with relatively preserved lung function, where individual pulmonary function variables provide no additional prognostic value, the performance of the $6 \mathrm{MWT}$ is prognostically important.

We also highlight the differences between various proposed criteria for IPF severity, reflecting the need for a standardised approach to disease severity stratification. While we found in our cohort a significant overlap using these various definitions for mild physiological impairment, there were also significant discrepancies. Furthermore, there was only fair concordance between FVC and DLco, with the FVC $\geq 80 \%$ classifying more patients as mild than DLco $\geq 55 \%$. This likely reflects the effects of the pulmonary function thresholds chosen, and was highlighted by the considerable variability in classification with different thresholds used in the exploratory analysis (see Additional file 3). The better concordance with composite values, as opposed to between single measures such as FVC and DLco, arises from the fact that both these single measures contribute to the calculation of the composite scores. It is interesting to note that the DLco and the composite scores were better at predicting survival suggesting that, while it is commonly used, the FVC threshold may not be the most clinically useful criteria.

Our study has several limitations. Firstly, this was a retrospective analysis of a prospective observational study and all investigations were performed as part of the patients' routine clinical care, resulting in some variability in the investigations performed. In particular, in clinical practice in Australia, there is variability between centres in routinely undertaking a 6MWT, for which we had baseline data for 164 individuals overall, and 63 patients in the groups with FVC $\geq 80 \%$. Despite the limited numbers, we were able to show a significant difference in outcomes, highlighting the strength of this 
association, a finding that we hope will now affect national clinical practice. Also, while there is a standardised guide for the 6MWT, there is likely to be variation between centres. The potential importance of this association between desaturation on 6MWT and prognosis also highlights the importance of confirming these findings in a larger, prospective cohort with standardised testing.

\section{Conclusion}

In summary, accurate clinical staging has important implications in IPF as it can inform initial patient management, prognostication and standardisation of clinical trials and their outcomes. Patients with mild physiological impairment have better overall survival, although their rate of disease progression appears the same as seen in those with moderate-severe impairment, with differences in outcome being attributable to where the patient sits in the natural history of their disease. Given their apparent identical disease trajectory and significant symptoms, this study adds impetus to the view that patients with mild impairment be offered anti-fibrotic therapy early in their disease course. This is particularly so for those with significant desaturation on the 6MWT, as they appear to have the poorest outcomes.

\section{Additional files}

Additional file 1: Table S1. GAP stage calculation. (DOC $30 \mathrm{~kb}$ )

Additional file 2: Table S2. Baseline characteristics of patients excluded from analysis. (DOC $35 \mathrm{~kb}$ )

Additional file 3: Figure S1. Exploratory analysis of varying thresholds. (PNG $100 \mathrm{~kb}$ )

Additional file 4: Figure S2. Locally Weighted Scatterplot Smoothing curves for FVC\% predicted. a. Mild physiological impairment (FVC $\geq 80 \%$ ). b. Moderate-severe physiological impairment (FVC $<80 \%$ ). c. Summary of LOWESS curve means. (ZIP $212 \mathrm{~kb}$ )

\section{Abbreviations}

6MWD: 6 min walk distance; 6MWT: 6 min walk test; AIPFR: Australian Idiopathic Pulmonary Fibrosis Registry; ASCEND: Assessment of Pirfenidone to Confirm Efficacy and Safety in Idiopathic Pulmonary Fibrosis; BMI: body mass index; CAPACITY: Clinical Studies Assessing Pirfenidone in idiopathic pulmonary fibrosis: Research of Efficacy and Safety Outcomes; COPD: chronic obstructive pulmonary disease; CPI: composite physiological index; DLco: diffusion capacity for carbon monoxide; FVC: forced vital capacity; GAP: Gender, Age, Physiology; ILD: interstitial lung disease; IPF: idiopathic pulmonary fibrosis; NHS: National Health Service; SD: standard deviation; SGRQ: St George's Respiratory Questionnaire; SpO2: peripheral blood oxygen saturation; TOMORROW: To improve pulmonary fibrosis with BIBF 1120; UCSD SOBQ: University of California San Diego shortness of breath questionnaire

\section{Acknowledgements}

The writers thank all the participants and physicians who contribute to the Registry, as well as the Registry secretariat and co-coordinators who work tirelessly to gather and collate information. We also thank Alfred Health Solutions and Alfred Medical Imaging who are integral to the development and maintenance of the web-based radiology database.

\section{Funding}

Lung Foundation Australia has established the Australian IPF Registry with the generous support of a philanthropic family and unrestricted educational grants from Foundation partners Roche Products, Pty. Limited and Boehringer Ingelheim and Project partner Bristol-Myers Squibb Australia. This analysis has been funded by support from the National Health and Medical Research Council (APP1066128). All data analysis, interpretation and writing was performed by the authors of the manuscript without input from funding bodies.

\section{Availability of data and materials}

All datasets used and/or analysed during the current study are available from the corresponding author on reasonable request.

\section{Authors' contributions}

HJ, TC and IG conceived the study. HJ analysed the data and together with TC, wrote the manuscript. All authors contributed to data collection and read and approved the final manuscript.

\section{Ethics approval and consent to participate}

The Registry has ethical approval to operate in all States and Territories of Australia. All participants provide informed written consent to have their data collected and entered into the Registry. This analysis has ethical approval from the Sydney Local Health District ethics committee (protocol No X14-0264) to utilise de-identified data.

\section{Consent for publication}

Not applicable. This manuscript does not contain any individual person's data in any form.

\section{Competing interests}

The authors declare that they have no competing interests.

\section{Publisher's Note}

Springer Nature remains neutral with regard to jurisdictional claims in published maps and institutional affiliations.

\section{Author details}

${ }^{1}$ Royal Prince Alfred Hospital, Missenden Road, Camperdown, NSW 2050, Australia. ${ }^{2}$ University of Sydney, Camperdown, NSW, Australia. ${ }^{3}$ The Alfred Hospital, Melbourne, VIC, Australia. ${ }^{4}$ Fiona Stanley Hospital, Murdoch, WA, Australia. ${ }^{5}$ Royal Adelaide Hospital, Adelaide, SA, Australia. ${ }^{6}$ The Austin Hospital, Heidelberg, VIC, Australia. ${ }^{7}$ Prince Charles Hospital, Chermside West, QLD, Australia. ${ }^{8}$ Princess Alexandria Hospital, Woolloongabba, QLD, Australia. ${ }^{9}$ School of Medicine, Western Sydney University, Parramatta, NSW, Australia.

${ }^{10} \mathrm{~S} c h o o l$ of Medicine, University of Tasmania, Hobart, TAS, Australia.

${ }^{11}$ University of Tasmania, Hobart, TAS, Australia. ${ }^{12}$ Royal Brisbane and Women's Hospital, Herston, QLD, Australia. ${ }^{13}$ John Hunter Hospital, New Lambton Heights, NSW, Australia. ${ }^{14}$ Lung Foundation Australia, Milton, QLD, Australia.

Received: 7 September 2017 Accepted: 4 January 2018

Published online: 25 January 2018

\section{References}

1. Raghu G, Collard HR, Egan JJ, Martinez FJ, Behr J, Brown KK, Colby TV, Cordier JF, Flaherty KR, Lasky JA, et al. An official ATS/ERS/JRS/ALAT statement: idiopathic pulmonary fibrosis: evidence-based guidelines for diagnosis and management. Am J Respir Crit Care Med. 2011;183(6):788-824.

2. Hutchinson J, Fogarty A, Hubbard R, McKeever T. Global incidence and mortality of idiopathic pulmonary fibrosis: a systematic review. Eur Respir J. 2015;46(3):795-806.

3. King TE Jr, Bradford WZ, Castro-Bernardini S, Fagan EA, Glaspole I, Glassberg MK, Gorina E, Hopkins PM, Kardatzke D, Lancaster L, et al. A phase 3 trial of pirfenidone in patients with idiopathic pulmonary fibrosis. N Engl J Med. 2014:370(22):2083-92.

4. Richeldi L, du Bois RM, Raghu G, Azuma A, Brown KK, Costabel U, Cottin V, Flaherty KR, Hansell DM, Inoue Y, et al. Efficacy and safety of nintedanib in idiopathic pulmonary fibrosis. N Engl J Med. 2014;370(22):2071-82.

5. Noble PW, Albera C, Bradford WZ, Costabel U, du Bois RM, Fagan EA, Fishman RS, Glaspole I, Glassberg MK, Lancaster L, et al. Pirfenidone for 
idiopathic pulmonary fibrosis: analysis of pooled data from three multinational phase 3 trials. Eur Respir J. 2016;47(1):243-53.

6. Richeldi L, Cottin V, du Bois RM, Selman M, Kimura T, Bailes Z, SchlenkerHerceg R, Stowasser S, Brown KK. Nintedanib in patients with idiopathic pulmonary fibrosis: combined evidence from the TOMORROW and INPULSIS trials. Respir Med. 2016;113:74-9.

7. Kolb M, Richeldi L, Behr J, Maher TM. Nintedanib in patients with idiopathic pulmonary fibrosis and preserved lung volume. Thorax. 2017;72(4):340-6

8. Albera C, Costabel U, Fagan EA, Glassberg MK, Gorina E, Lancaster L, Lederer DJ, Nathan SD, Spirig D, Swigris JJ. Efficacy of pirfenidone in patients with idiopathic pulmonary fibrosis with more preserved lung function. Eur Respir J. 2016;48(3):843-51.

9. Kolb M, Collard HR. Staging of idiopathic pulmonary fibrosis: past, present and future. Eur Respir Rev. 2014;23(132):220-4.

10. Sharp C, Adamali HI, Millar AB. A comparison of published multidimensional indices to predict outcome in idiopathic pulmonary fibrosis. ERJ open research. 2017:3:1.

11. King TE Jr, Tooze JA, Schwarz MI, Brown KR, Cherniack RM. Predicting survival in idiopathic pulmonary fibrosis: scoring system and survival model. Am J Respir Crit Care Med. 2001;164(7):1171-81.

12. Mogulkoc N, Brutsche MH, Bishop PW, Greaves SM, Horrocks AW, Egan JJ, Greater Manchester Pulmonary Fibrosis C. Pulmonary function in idiopathic pulmonary fibrosis and referral for lung transplantation. Am J Respir Crit Care Med. 2001;164(1):103-8.

13. Erbes $R$, Schaberg $T$, Loddenkemper R. Lung function tests in patients with idiopathic pulmonary fibrosis. Are they helpful for predicting outcome? Chest. 1997;111(1):51-7.

14. Wells AU, Desai SR, Rubens MB, Goh NS, Cramer D, Nicholson AG, Colby TV, du Bois RM, Hansell DM. Idiopathic pulmonary fibrosis: a composite physiologic index derived from disease extent observed by computed tomography. Am J Respir Crit Care Med. 2003;167(7):962-9.

15. Ley B, Ryerson CJ, Vittinghoff E, Ryu JH, Tomassetti S, Lee JS, Poletti V, Buccioli M, Elicker BM, Jones KD, et al. A multidimensional index and staging system for idiopathic pulmonary fibrosis. Ann Intern Med. 2012; 156(10):684-91.

16. Jo HE, Glaspole I, Grainge C, Goh N, Hopkins PM, Moodley Y, Reynolds PN, Chapman S, Walters EH, Zappala C, et al. Baseline characteristics of idiopathic pulmonary fibrosis: analysis from the Australian idiopathic pulmonary fibrosis registry. Eur Respir J. 2017:49:2.

17. Lederer DJ, Arcasoy SM, Wilt JS, D'Ovidio F, Sonett JR, Kawut SM. Sixminute-walk distance predicts waiting list survival in idiopathic pulmonary fibrosis. Am J Respir Crit Care Med. 2006;174(6):659-64.

18. Caminati A, Bianchi A, Cassandro R, Mirenda MR, Harari S. Walking distance on 6-MWT is a prognostic factor in idiopathic pulmonary fibrosis. Respir Med. 2009;103(1):117-23

19. du Bois RM. 6-minute walk distance as a predictor of outcome in idiopathic pulmonary fibrosis. Eur Respir J. 2014;43(6):1823-4.

20. Flaherty KR, Andrei AC, Murray S, Fraley C, Colby TV, Travis WD, Lama V, Kazerooni EA, Gross BH, Toews GB, et al. Idiopathic pulmonary fibrosis: prognostic value of changes in physiology and six-minute-walk test. Am J Respir Crit Care Med. 2006;174(7):803-9.

21. Hallstrand TS, Boitano LJ, Johnson WC, Spada CA, Hayes JG, Raghu G. The timed walk test as a measure of severity and survival in idiopathic pulmonary fibrosis. Eur Respir J. 2005;25(1):96-103.

\section{Submit your next manuscript to BioMed Central and we will help you at every step:}

- We accept pre-submission inquiries

- Our selector tool helps you to find the most relevant journal

- We provide round the clock customer support

- Convenient online submission

- Thorough peer review

- Inclusion in PubMed and all major indexing services

- Maximum visibility for your research

Submit your manuscript at www.biomedcentral.com/submit

Biomed Central 